\title{
DNA CIRCLES WITH CRUCIFORMS FROM ISOSPORA (TOXOPLASMA) GONDII
}

\author{
P. BORST ${ }^{a}, *$ J.P. OVERDULVE ${ }^{b}$, P.J. WEIJERS ${ }^{a}$, F. FASE-FOWLER ${ }^{a, *}$ and M. VAN DEN BERG ${ }^{\text {a }}$ \\ a Section for Medical Enzymology, Laboratory of Biochemistry, University of Amsterdam, P.O. Box 60.000, 1005 GA Amsterdam, and \\ ${ }^{b}$ Department of Tropical Veterinary Medicine and Protozoology, State University Utrecht, P.O. Box 80.172 3508 TD Utrecht (The \\ Netherlands)
}

(Received September 5th, 1983)

Key words: Cruciform DNA; Branch migration; Circular DNA; Electron microscopy; (I. (Toxoplasma) gondii)

We have isolated a closed circular duplex DNA fraction from the unicellular parasite Isospora (Toxoplasma) gondii and examined the purified DNA by electron microscopy. A major part of this circular DNA consists of $12-\mu \mathrm{m}$ circles containing a cruciform with $0.5-\mu \mathrm{m}$ tails. We also found $23-\mu \mathrm{m}$ circles with the properties expected of head-to-tail dimers of the $12-\mu \mathrm{m}$ circles. Some of these dimers have two cruciforms with $0.4-\mu \mathrm{m}$ tails, some have one cruciform with $0.8-\mu \mathrm{m}$ tails. When ethidium bromide was diffused into the DNA solution, circles with tails were replaced by twisted circles without tails. Direct mixing of the DNA with high ethidium bromide concentrations $(5 \mu \mathrm{g} / \mathrm{ml})$ gave rise to highly twisted circles with tails. This proves that the tailed circles are covalently continuous and indicates that ethidium bromide blocks branch migration. The $0.5-\mu \mathrm{m}$ tails are part of a $1.7-\mu \mathrm{m}$ palindrome, which was visualized by spreading denatured DNA under snap-back conditions. We argue that the cruciform is not present in vivo and that the $12-\mu \mathrm{m}$ circles may represent the mitochondrial DNA of Toxoplasma.

\section{Introduction}

Circular DNAs in which both strands are covalently continuous are widespread in nature [1-5]. Upon isolation, these DNAs are nearly always supertwisted and the superhelical turns are always right-handed, i.e., they have the same handedness as the turns in the DNA helix of B-DNA. Most covalently continuous DNAs in nature have average superhelix densities $(\sigma)$ between -0.03 and -0.09 , i.e., 3-9 superhelical turns per $\mathrm{kb}$. The usual values are between -0.06 and -0.09 [2].

The underwound state of covalently continuous

\footnotetext{
* Present address: Antoni van Leeuwenhoekhuis, The Netherlands Cancer Institute, Plesmanlaan 121, $1066 \mathrm{CX}$ Amsterdam, The Netherlands.

Abbreviations: bp, basepair(s); kb, kilo basepair(s).
}

DNA in vivo could have a passive or active origin (cf. Ref. 6). Passive underwinding could arise when a protein that unwinds the helix is bound to covalently continuous DNA in the presence of a topoisomerase that relaxes supercoils. The resulting DNA is distorted, but relaxed in vivo. The distortion is converted into supercoils in vitro when the protein is removed during DNA isolation. Active underwinding can be maintained by DNA gyrase, an enzyme that introduces right-handed supercoils into DNA at the cost of ATP hydrolysis (see Ref. 3). Experiments with purified gyrase have shown $[6,7]$ that it can raise the negative superhelix density of covalently continuous DNA up to 0.10 , i.e., above that found in nature. Evidence that DNA gyrase also maintains a certain degree of superhelicity in vivo has come from studies on gyrase inhibitors and topoisomerase I mutants of Enterobacteriae (see Ref. 8). Inhibition of gyrase 
with coumermycin or other inhibitors not only blocks DNA replication, but also prevents the synthesis of a variety of mRNAs. Conversely, mutations that prevent the synthesis of topoisomerase I lead to the pleiotropic activation of the transcription of many genes, suggesting that a higher steady state of negative superhelicity will facilitate transcription of operons that otherwise require the help of additional DNA unwinding proteins to activate transcription. These results support the idea that at least part of the supertwists found in isolated bacterial covalently continuous DNAs was already there in vivo. The identity of this part has been investigated by Sinden and Pettijohn $[9,10]$, using photobinding of trimethylpsoralen to DNA which is proportional to the negative superhelicity of the DNA even in vivo. In Escherichia coli they found with this technique a superhelix density of -0.05 . This underwinding was largely abolished by gyrase inhibitors, suggesting that most of the supertwists in bacterial DNA are actively maintained by gyrase action.

Another approach to this problem is provided by the presence of inverted repeats in DNA. Interest in these structures stems from their possible role in protein binding [11] and has been stimulated by the fact that inverted repeats are overrepresented in DNA regions with regulatory significance [12]. Like promoters, these repeats are indicators of the superhelicity of DNA because they can exist in two configurations: linear and cruciform. In DNA without supertwists the linear form is favoured even if the cruciform contains perfect hairpins. The reason is that cruciforms always contain some non-paired bases in the top of the hairpin, which are paired in the linear form $[13,14]$. The torsional stress in superhelical covalently continuous DNA will, however, tend to unwind the DNA helix and this process will be facilitated when the denatured segments can basepair as cruciform. Theoretical considerations indicate that the negative superhelicities found in covalently continuous DNAs in nature provide sufficient driving force to generate cruciforms from perfect long palindromes [13-16].

Indirect evidence that short cruciforms are actually present in supertwisted covalently continuous DNA comes from experiments with $S_{1}$ nuclease, which cuts single-stranded regions in
DNA. In several isolated DNAs this enzyme preferentially cuts at the joint of short inverted repeats and this cut is prevented by relaxing the superhelical turns [17-19]. Direct evidence for the formation of cruciforms in supertwisted DNA was obtained by recent in vitro studies of plasmid DNAs with short natural imperfect palindromes $[20,21]$ or longer (constructed) perfect palindromes (Refs. 6, 7, 34; and Gellert, M., personal communication). Using electron microscopy and gel analysis to monitor cruciform formation, both groups found that cruciforms are already stable at a negative superhelix density as low as 0.03 .

Long, perfect, inverted repeats could also be used to help assess the steady state of active supercoiling in vivo. If this is high enough to drive an inverted repeat into its cruciform isomer, the isolated covalently continuous DNA would be expected to contain the inverted repeat completely as cruciform in addition to having supertwists in the remainder of the molecule. If, however, the supertwists found in vitro after isolation of the DNA largely originate from passive distortion of the helix in vivo by protein binding or other intracellular conditions, one would expect the covalently continuous DNA to have no cruciform or a cruciform commensurate with the standard superhelix density usually found in covalently continuous DNAs.

The covalently continuous DNAs with long palindromes required to test these ideas are rare in nature, probably because such molecules are usually unstable $[6,7,22]$. We have recently found, however, a covalently continuous DNA with a long palindrome in Isospora (Toxoplasma) gondii, the most common protozoan parasite of homeothermal vertebrates, including man. The analysis of this DNA, presented here, indicates that it does not exist as cruciform in vivo, even though the superhelix density of this molecule is sufficient to drive the inverted repeat partially into cruciform in vitro. This suggests that the underwound state of this circular DNA must at least in part have a passive origin.

\section{Methods}

Isolation of DNA from Isospora (Toxoplasma) gondii. The KB strain of Isospora (Toxoplasma) 
gondii [23], made virulent in May 1979 by rapid serial passages (three times a week) in mice and maintained in the same way for more than 2 years (over 300 passages), was inoculated into 110 SPF female Swiss mice (TNO Proefdierenbedrijf, Zeist, The Netherlands), weighing 25-30 g, each mouse receiving about $10^{6}$ parasites. After 3 days the peritoneal exudate was collected with phosphatebuffered saline $\left(140 \mathrm{mM} \mathrm{NaCl}, 4.5 \mathrm{mM} \mathrm{Na}_{2} \mathrm{HPO}_{4}\right.$, $1.3 \mathrm{mM} \mathrm{NaH} \mathrm{PO}_{4}$ (pH 7.2); 2-2.5 ml per mouse) by puncture through the intact bared peritoneum, washed by sedimentation and concentrated. The final pellet contained about $10^{10}$ Toxoplasma cells, about $1 \mathrm{~g}$ wet weight, equivalent to about $1.15 \mathrm{mg}$ DNA (as estimated previously by cytophotometry [24] in a similar population - a 3-days old infection in mice - of rapidly proliferating parasites of the same strain). About $10 \%$ of the cells in the pellet consisted of contaminating host leucocytes and traces of red cells. Extraction and purification of DNA from the parasites followed our protocol used for trypanosome DNA [25]. The cells were resuspended in $10 \mathrm{ml}$ buffer containing $0.1 \mathrm{M}$ $\mathrm{NaCl}, 0.01 \mathrm{mM}$ sodium EDTA (pH 7.5) (which induced partial lysis), rapidly followed by Sarkosyl and pronase addition to final concentrations of 3\% and $1 \mathrm{mg} / \mathrm{ml}$, respectively. After $2 \mathrm{~h}$ at $37^{\circ} \mathrm{C}, 500$ $\mu \mathrm{g}$ pronase were added per $\mathrm{ml}$ and the incubation was continued overnight at $4^{\circ} \mathrm{C}$. After two extractions with chloroform/isoamyl alcohol $(24: 1)$, the nucleic acid solution was centrifuged to equilibrium in NaI, containing $100 \mu \mathrm{g}$ ethidium bromide per $\mathrm{ml}$. The gradient was run in a Beckman Spinco 40 -angle rotor at $20^{\circ} \mathrm{C}$ for $72 \mathrm{~h}$ at $36000 \mathrm{rpm}$ and then for an additional $17 \mathrm{~h}$ at $30000 \mathrm{rpm}$. The broad fluorescent DNA band was collected by syringe, extracted three times with amyl alcohol to remove the ethidium bromide and then dialysed into $10 \mathrm{mM}$ Tris- $\mathrm{HCl}(\mathrm{pH} 7.5)$. After dialysis the nucleic acid solution was incubated for $1 \mathrm{~h}$ at $37^{\circ} \mathrm{C}$ with $100 \mu \mathrm{g}$ pancreas ribonuclease $/ \mathrm{ml}$ and 10 units $T_{1}$ ribonuclease $/ \mathrm{ml}$. After addition of Sarkosyl to a final concentration of $0.1 \%$ and pronase to $200 \mu \mathrm{g} / \mathrm{ml}$, the incubation was continued for $2 \mathrm{~h}$ at $37^{\circ} \mathrm{C}$. The solution was then extracted with chloroform/phenol $(1: 1)$, potassium acetate was added to a final concentration of $0.1 \mathrm{M}$ and the DNA was precipitated with $2 \mathrm{vol}$. of ethanol at $-20^{\circ} \mathrm{C}$. The precipitate was col- lected by centrifugation and washed once with $70 \%$ ethanol. The DNA pellet was resuspended in $10 \mathrm{mM}$ Tris- $\mathrm{HCl}$ (pH 7.5).

$300 \mu \mathrm{g}$ of the purified Toxoplasma DNA were centrifuged to equilibrium in a $\mathrm{CsCl}$ gradient containing $100 \mu \mathrm{g}$ ethidium bromide per ml. Parallel tubes contained $30 \mu \mathrm{g}$ of phage PM2 DNA and 30 $\mu \mathrm{g}$ of pBR322 plasmid DNA. A Beckman Spinco SW-50 rotor was used, running for $40 \mathrm{~h}$ at 44000 $\mathrm{rpm}$ at $20^{\circ} \mathrm{C}$. At the end of the run both phage PM2 DNA and pBR322 plasmid DNA gave two clearly separated bands. Toxoplasma DNA gave only a single broad band corresponding in position to the band with the open circular DNA of the two marker DNAs. The DNA-containing band and the zone below this band, corresponding to the position where closed circular Toxoplasma DNA would be expected to equilibrate, were separately collected, the ethidium bromide was extracted with amyl alcohol and the $\mathrm{CsCl}$ was removed by dialysis against $10 \mathrm{mM}$ Tris- $\mathrm{HCl}(\mathrm{pH}$ 7.5).

Electron microscopy. The standard spreading procedure as described in Ref. 26 was used in a slightly modified form. The final concentrations of reagents in the spreading solution were $40 \%$ formamide, $100 \mathrm{mM}$ Tris- $\mathrm{HCl}(\mathrm{pH} 8.5), 10 \mathrm{mM}$ $\mathrm{Na}_{2}$ EDTA, $100 \mathrm{mM} \mathrm{NaCl}$ and $0.01 \%$ cytochrome c. DNA was added in a concentration of 0.1 $\mu \mathrm{g} / \mathrm{ml}$. The hypophase contained $10 \mathrm{mM}$ Tris- $\mathrm{HCl}$ (pH 8.5), $1 \mathrm{mM} \mathrm{Na}{ }_{2}$ EDTA. Formamide was twice crystallized and all solutions were made in distilled water that was in addition twice distilled in a quartz apparatus.

DNA preparations were denatured in $10 \mathrm{mM}$ Tris- $\mathrm{HCl}$ ( $\mathrm{pH} \mathrm{8.5),} 1 \mathrm{mM} \mathrm{Na}{ }_{2}$ EDTA by heating at $90^{\circ} \mathrm{C}$ during $2 \mathrm{~min}$ and immediately quenched in ice. The spreading solution of these denatured DNA preparations contained in final concentrations $0.16 \mu \mathrm{g}$ DNA per $\mathrm{ml}, 10 \mathrm{mM}$ Tris- $\mathrm{HCl}(\mathrm{pH}$ 8.5), $1 \mathrm{mM} \mathrm{Na}{ }_{2}$ EDTA, $10 \mathrm{mM} \mathrm{NaCl}, 40 \%$ formamide and $0.01 \%$ cytochrome $c$. The hypophase contained $10 \mathrm{mM}$ Tris- $\mathrm{HCl}(\mathrm{pH} 8.5), 1 \mathrm{mM}$ $\mathrm{Na}_{2}$ EDTA. Under these conditions the snap-back DNA palindromes and single-stranded DNA are nicely stretched.

Diffusion of ethidium bromide into the DNA solution was done by filling a small capillary glass pipette (total volume $100 \mu \mathrm{l}$ ) with $10 \mu \mathrm{l}$ DNA 
solution in $0.2 \mathrm{M}$ Tris- $\mathrm{HCl}(\mathrm{pH} 8.5), 1 \mathrm{mM}$ $\mathrm{Na}_{2}$ EDTA, $0.2 \mathrm{M} \mathrm{NaCl}$ and adjacent to this $10 \mu \mathrm{l}$ of ethidium bromide solution. The capillary was turned upside down and held in this position during $2 \mathrm{~h}$ in the dark. In this way the ethidium bromide diffused slowly into the total volume of the liquid in the capillary. For spreading, the last 5 $\mu 1$ of the total volume of $20 \mu 1$ present in the pipette were added to the spreading solution as described above for double-standed DNA. Four different concentrations of ethidium bromide $(0.01$, $0.1,1$ and $5 \mu \mathrm{g} / \mathrm{ml}$ ) were used in different capillary pipettes. The hypophase for these spreadings had the same ethidium bromide concentrations as present in the incubations.

Copper grids (200 mesh), covered with parlodion films, were used to pick up the DNA-cytochrome $c$ film from the hypophase, followed by staining with uranyl acetate according to Davis and Davidson [27] and rotary shadowing with $\mathrm{Pt} / \mathrm{Pd}(80 / 20)$. A Philips EM 300 electron microscope was used to take pictures of the molecules at a magnification of $5500 \times$. The magnification was calibrated with a grating replica (Fulham 2160 lines $/ \mathrm{mm}$ ). Length measurements were done on 10-fold enlargements of the negatives from which the respective molecules were drawn on paper. For measuring, a tablet digitizer (Summagrafics, Fairfield, CT, U.S.A.) connected to a calculator (HP 9825 A) was used. The DNA preparations contained many $5-\mu \mathrm{m}$ circles, probably originating from contaminating mitochondria of the leucocytes of the inoculated mice. All measurements of double-stranded DNA molecules were corrected relative to these $5-\mu \mathrm{m}$ circles present on the same grids, their size being taken as $5.1 \mu \mathrm{m}$ [28]. In denatured Toxoplasma DNA preparations phage PM2 DNA molecules were added as internal length standard (3.22 $\mu \mathrm{m}[29])$.

$S_{1}$ nuclease incubation (see Ref. 30). Samples of purified Toxoplasma DNA were incubated with $\mathrm{S}_{1}$ nuclease (Sigma) at $37^{\circ} \mathrm{C}$ in $30 \mathrm{mM}$ sodium acetate, $50 \mathrm{mM} \mathrm{NaCl}, 1 \mathrm{mM} \mathrm{ZnSO}$ (pH 4.6). After an incubation varying between 5 and $30 \mathrm{~min}$, the reaction was stopped by adding $10 \mathrm{mM} \mathrm{Na}{ }_{2}$ EDTA (pH 8.0). The DNA was analysed by electron microscopy without further purification.

\section{Results}

We have extracted total cellular DNA from Toxoplasma grown in mice and centrifuged this to equilibrium in a $\mathrm{CsCl}$-ethidium bromide gradient. Only a single fluorescent band was present at a density corresponding to the linear covalently continuous DNA bands of plasmid pBR322 and phage PM2 DNA centrifuged in parallel gradients in the same experiment. The invisible DNA present in the region below the main band was collected, purified and examined by electron microscopy, using a formamide version [26] of the Kleinschmidt protein-monolayer technique [31]. In addition to linear DNA, this fraction contained three types of circular molecule (see Fig. 1).

1. An apparently homogeneous class of circles with a contour length of about $5 \mu \mathrm{m}$. These are probably mouse mitochondrial DNA molecules [32] derived from the mouse leucocytes that contaminated the Toxoplasma cells.

2. Larger duplex DNA circles, varying in size between 8 and $30 \mu \mathrm{m}$, with a peak at $12 \mu \mathrm{m}$.

3. Circles with tails, as illustrated in Fig. 2.

The open rectangles in Fig. 1 present the length distribution of the tailed circles. Most of the circles

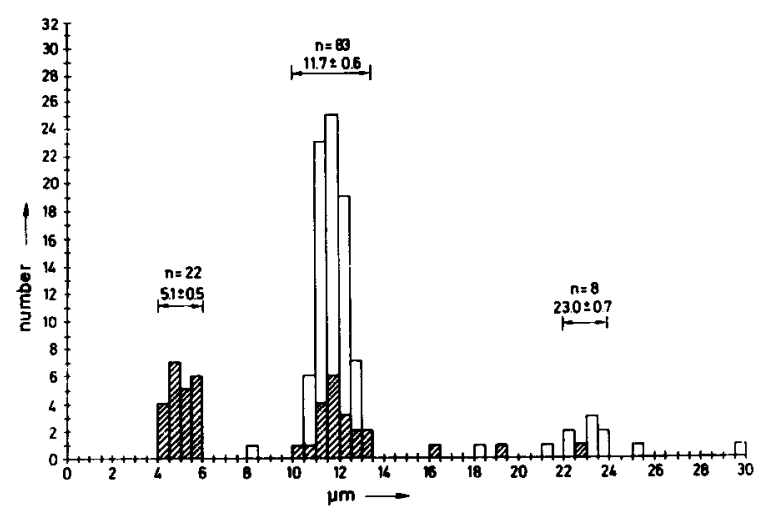

Fig. 1. Length distribution of circular DNA molecules present in the covalently continuous DNA fraction from Toxoplasma. The DNA fraction was obtained by $\mathrm{CsCl}$-ethidium bromide centrifugation and the contour length of circular molecules was determined by electron microscopy as described in Methods. The hatched blocks represent circular molecules without tails. The $5-\mu \mathrm{m}$ molecules probably originate from mitochondria from contaminating mice cells. The open blocks represent circles with tails. The tails are included in the contour length values. 

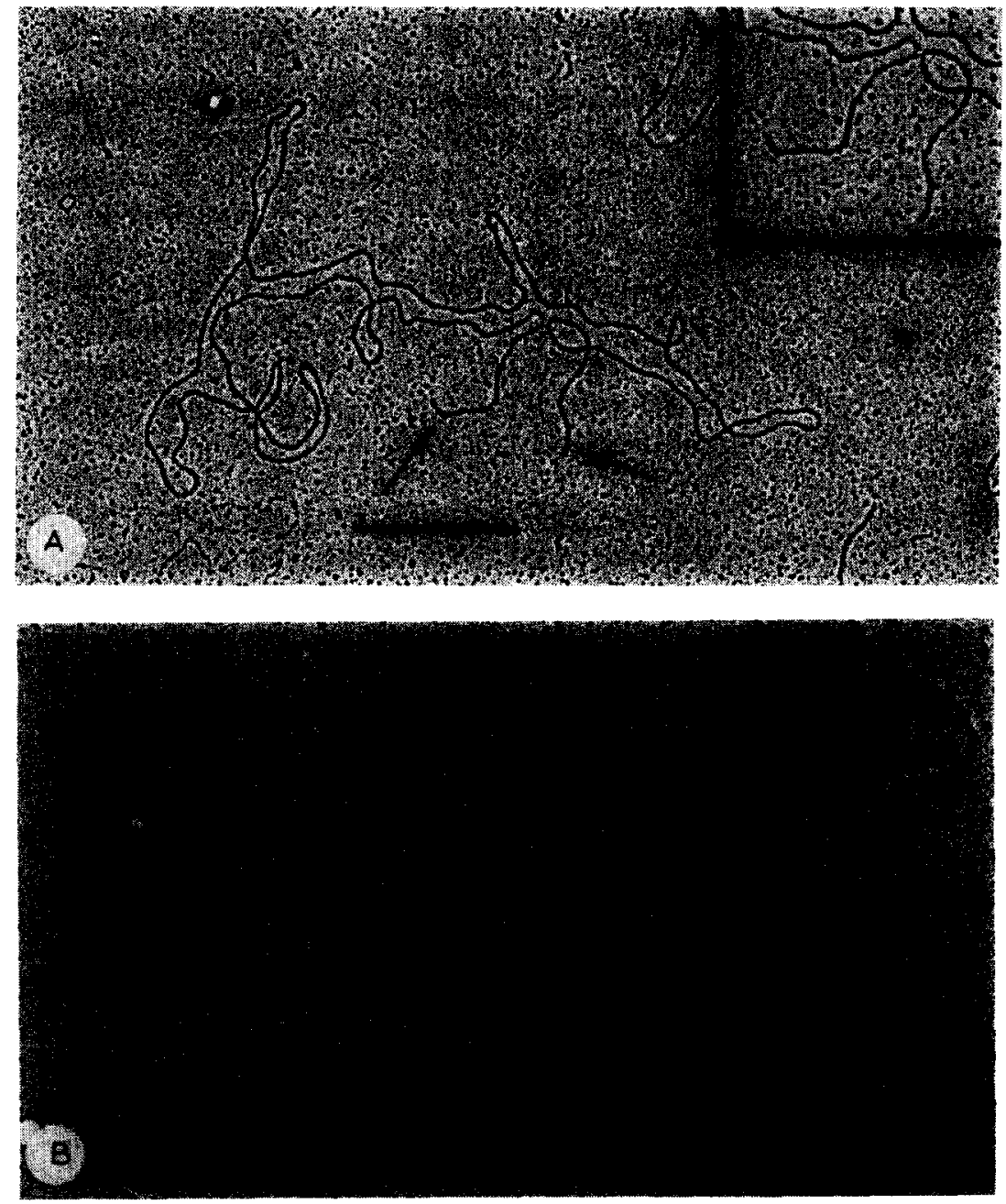

Fig. 2. Electron micrographs of tailed 12 $\mu \mathrm{m}$ circles in the covalently continuous DNA fraction from Toxoplasma. The insets show the 'eyes' at the base of the tails. See Methods for details. The bar is $0.5 \mu \mathrm{m}$.

form a homogeneous peak at $11-12 \mu \mathrm{m}$, coinciding with the main peak of circles without tails, but there is a small second peak at $23 \mu \mathrm{m}$.

The two tails in one circle are of equal size (Table I) and the crossover contains a highly characteristic 'eye' (see insets in Fig. 2). The obvious interpretation is that the tailed circles are closed palindrome-containing circles that have used their right-handed supertwists to drive the long palindrome into a cruciform. The presence of a long duplication-inversion was directly demonstrated by spreading the DNA for electron microscopy after denaturation under conditions where single-stranded DNA remains stretched. These DNA preparations contained linear DNA molecules with a $1.7-\mu \mathrm{m}$ duplex branch and an occa- sional single-stranded circle with a $1.7-\mu \mathrm{m}$ tail (Fig. 3). No other duplex DNA (besides the phage PM2 DNA added as marker) was detectable in these preparations. Hence the duplex tails must have arisen from snap-back of a palindrome rather than by bi-molecular renaturation between molecules. Table I shows that the snap-back palindrome is much longer than the tails in the duplex molecules in Fig. 2. It covers nearly $30 \%$ of the circle. We return to this point below.

The closed nature of the tailed duplex circles is not obvious from Fig. 2. There is only one crossover in the circle in Fig. 2B and the average number of crossovers in ten tailed circles was not different from that in ten non-tailed $12-\mu \mathrm{m}$ circles present on the same grid (1.5 versus 1.3 ). To verify 
TABLE I

SIZE OF DUPLEX PARTS OF TAILED DUPLEX CIRCLES AND DENATURED CIRCLES IN TOXOPLASMA DNA

\begin{tabular}{|c|c|c|c|c|}
\hline & \multicolumn{4}{|c|}{ Size in $\mu \mathrm{m}$} \\
\hline & $\overline{\text { Mean }}$ & S.D. & Range & $\bar{n}$ \\
\hline \multicolumn{5}{|l|}{ Duplex monomer circles } \\
\hline Single tail & 0.49 & 0.08 & 0.26 & 50 \\
\hline Difference between tails present in one molecule & 0.03 & 0.02 & 0.09 & 26 \\
\hline Circle including tails & 11.8 & 0.10 & 2.1 & 24 \\
\hline \multicolumn{5}{|l|}{ Duplex dimer circles with four tails } \\
\hline Single tail & 0.42 & 0.03 & 0.10 & 8 \\
\hline Circle including tails & 23.4 & 0.03 & 0.04 & 2 \\
\hline Difference between tails of same pair & 0.03 & 0.02 & 0.03 & 4 \\
\hline \multicolumn{5}{|l|}{ Duplex dimer circles with two tails } \\
\hline Single short tail & 0.44 & 0.00 & 0.00 & 1 \\
\hline Single long tail & 0.81 & 0.03 & 0.07 & 8 \\
\hline Difference between long tails present in one molecule & 0.05 & 0.03 & 0.07 & 4 \\
\hline Circle including tails & 23.0 & 0.69 & 1.6 & 5 \\
\hline \multicolumn{5}{|l|}{ Denatured DNA } \\
\hline Duplex tail & 1.69 & 0.02 & 0.32 & 26 \\
\hline
\end{tabular}

the closed nature of the tailed circles, the DNA was spread in the presence of ethidium bromide. When mixed with high concentrations of ethidium

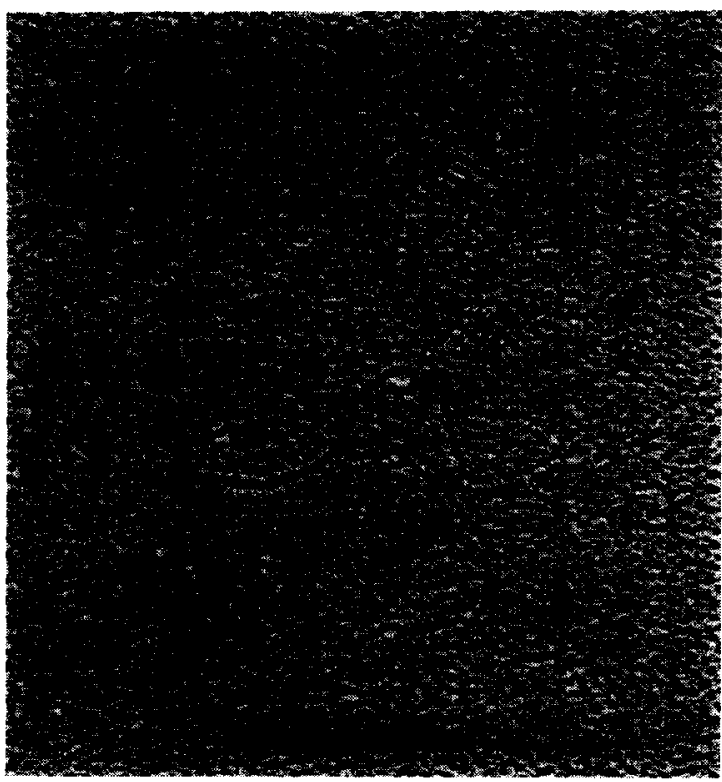

Fig. 3. Electron micrograph of a denatured DNA circle from Toxoplasma, spread under conditions allowing renaturation of palindromic DNA. See Methods for details. The bar is $0.5 \mu \mathrm{m}$. bromide $(5 \mu \mathrm{g} / \mathrm{ml})$, part of the circles became highly twisted. Although difficult to trace, most of these circles had unambiguous tails, as shown in Fig. 4A. In 18 molecules in which the tails were sufficiently unentangled, their average size was $0.41 \pm 0.06 \mu \mathrm{m}$, which is similar to $0.49 \pm 0.08 \mu \mathrm{m}$ found for tailed circles spread in the absence of ethidium bromide. These results strongly support the contention that the tailed circles are closed, but the preservation of the tails in the presence of ethidium bromide was unexpected. The twists induced by ethidium bromide are left-handed and the cruciform should, therefore, have disappeared in the twisted molecules. To test whether a high degree of ethidium bromide intercalation could slow down unwinding of the helix to such an extent that the cruciform would become fixed, the concentration of ethidium bromide was raised more slowly by letting it diffuse into the DNA solution (see Methods). After this procedure, most of the twisted circles lacked tails as illustrated in Fig. 4B. The increase in the fraction of twisted circles with a concomitant decrease of tailed circles shown in Fig. 5 agrees with the interpretation that the former are derived from the latter.

As shown in Fig. 1, the preparations also contained tailed circles about twice the size of the 


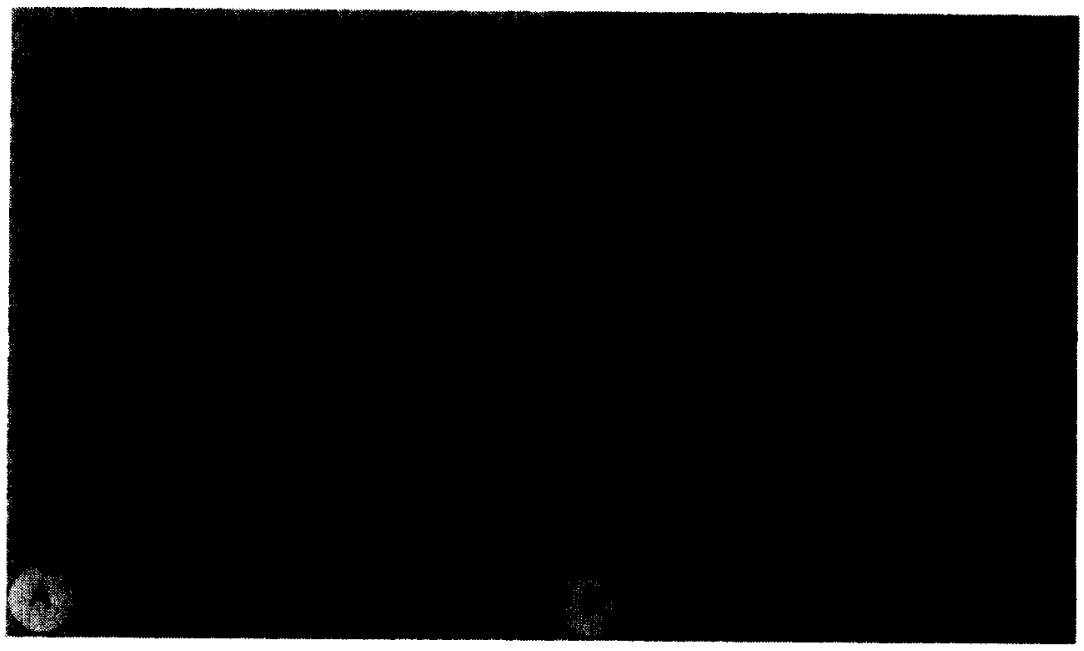

Fig. 4. Electron micrographs of covalently continuous DNA from Toxoplasma containing bound ethidium bromide. A: DNA mixed with $5 \mu \mathrm{g}$ ethidium bromide per $\mathrm{ml}$ and spread. Note the tails in this twisted circle. B: DNA exposed to a slowly rising ethidium bromide concentration as described in Methods. The bar is $0.5 \mu \mathrm{m}$.

$12-\mu \mathrm{m}$ circles. These circular dimers were of three types: circles containing four tails of the size found in monomer $12-\mu \mathrm{m}$ circles (Fig. $6 \mathrm{~A}$ ); circles containing only two tails, but of double length (Fig. 6B); and a single circle containing only two 'short' tails of the size found in monomer circles. The size (see Table I) and position (Fig. 6) of the tails are

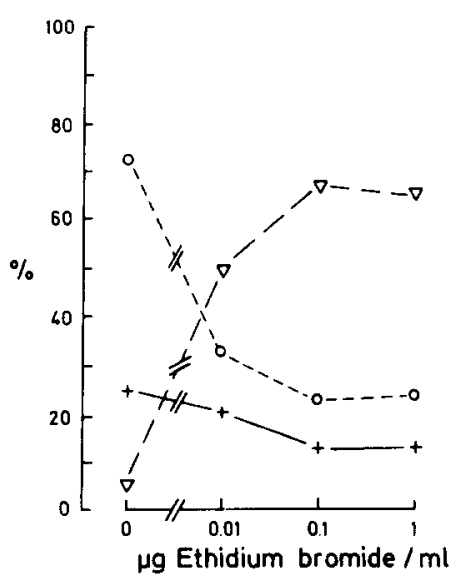

Fig. 5. Effect of ethidium bromide on topoisomers of the $12-\mu \mathrm{m}$ monomer and $24-\mu \mathrm{m}$ circles in Toxoplasma DNA. Ethidium bromide was allowed to diffuse into a solution containing Toxoplasma DNA and the DNA was analysed by electron microscopy (see Methods for details). +-+ open circles without tails; $\bigcirc . . . . . \bigcirc$, circles with tails; $\nabla-\ldots .-\nabla$, highly supercoiled circles with and without tails. The concentration of ethidium bromide is on a log scale. The number of molecules counted was $46,37,45$ and 26 for the successive concentrations of ethidium bromide. those expected for dimers of the monomeric circle shown in Fig. 2. In the Toxoplasma DNA preparation with the highest fraction of tailed circles, the monomer/dimer ratio was $110 / 35=3$ on a number basis. The dimers represent, therefore, a substantial fraction of the tailed circles.

\section{Discussion}

The origin of the tailed circles

We have characterized in this paper a class of tailed circular molecules from Toxoplasma preparations. Toxoplasma is difficult to obtain in large amounts in a pure state and the characterization is, therefore, not rigorous. Tailed circles have never been seen in mouse DNA and this justifies our conclusion that these molecules are derived from the parasite rather than from contaminating host cells. The circles have the size expected for a protozoan mitochondrial DNA, but their origin from mitochondria remains to be demonstrated. Our attempts to demonstrate enrichment of the circles in mitochondrial preparations have only yielded degraded DNA, probably because the mitochondria of Toxoplasma are very large and elongate and, therefore, easily broken during isolation. Because only small amounts of impure circles were obtained, we have restricted ourselves to electron microscopy for their characterization. The circles represented a minority of the DNA molecules present in these preparations and we have, therefore, not proven that the molecules in Figs. 

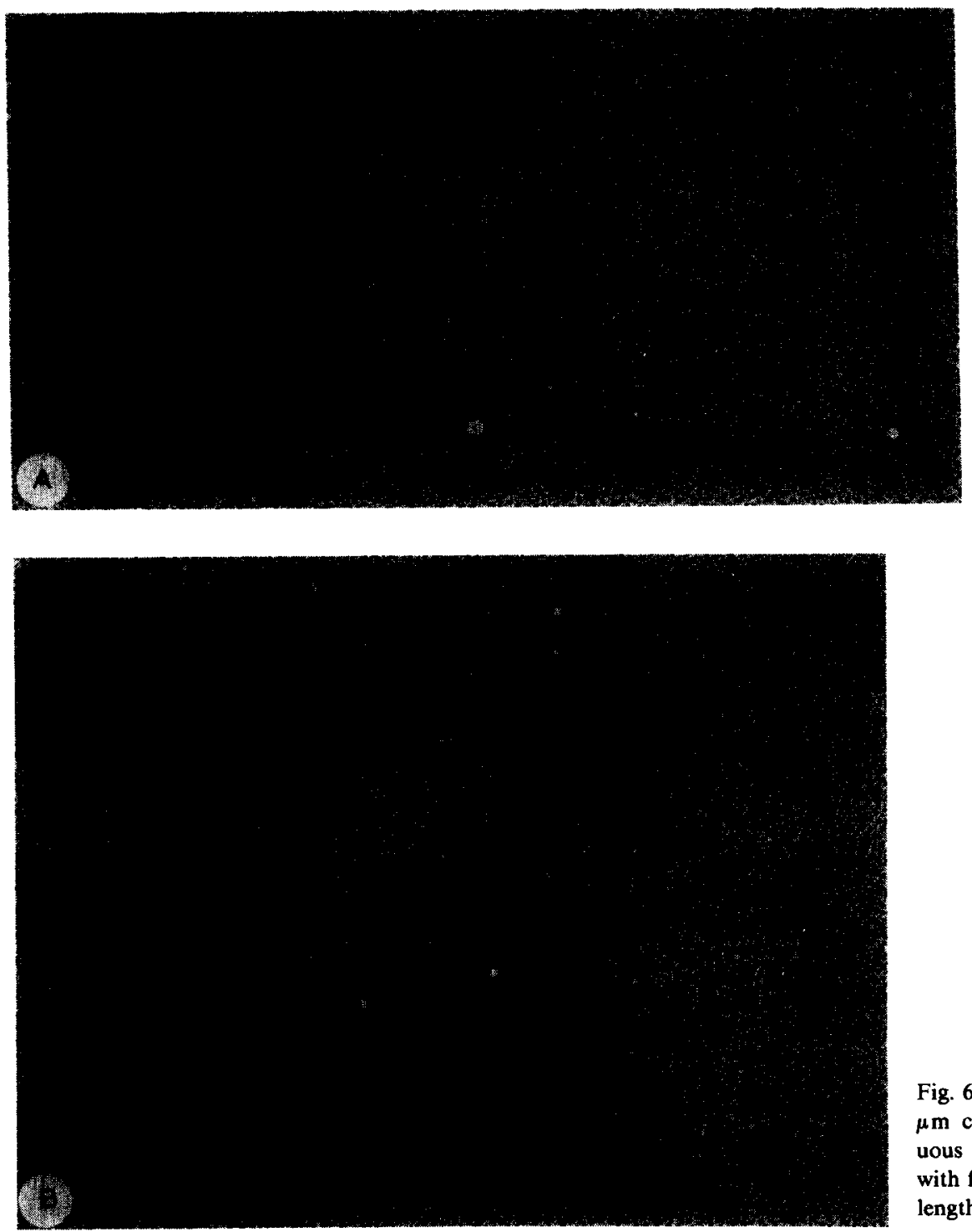

Fig. 6. Electron micrographs of tailed 23$\mu \mathrm{m}$ circles present in covalently continuous DNA from Toxoplasma. A: circle with four tails; B: circle with two doublelength tails. The bar is $0.5 \mu \mathrm{m}$.

2-4 all represent the same class of circles. This is very likely, however, in view of the highly characteristic appearance of these molecules. The only reasonable interpretation of our results is, therefore, that Toxoplasma contains a single homogeneous class of $12-\mu \mathrm{m}$ DNA circles, each with a single palindrome which spans $3.4 \mu \mathrm{m}$.

Recent cytophotometric investigations on microgametes of Toxoplasma [24] indicate that the amount of mitochondrial DNA is about $3 \mathrm{fg}$ per cell, equivalent to $2730 \mathrm{~kb}$. If all the mitochondrial DNA of Toxoplasma is composed of $12-\mu \mathrm{m}$ circles, each Toxoplasma cell should contain about 76 of these circles. This is similar to the number of mitochondrial DNA molecules found in other unicellular eukaryotes, e.g., yeast [33].

The relevance of tailed circles for phylogenetic studies on Coccidia

After the successive discovery of sexuality in Toxoplasma, Sarcosystis, Besnoitia and related Coccidia in the seventies, phylogenetic relationships within the Coccidia and their relationship to other Sporozoa have been the subject of much 
speculation and controversy. The discussion was especially hampered by the uncertainty about the phylogenetic relevance of phenotypic characters such as host specificity, homoxeny and facultative or obligatory heteroxeny, life-cycle patterns and modes of transmission, immunological and ultrastructural characteristics of successive stages, etc. The presence of a morphologically recognizable inverted repeat in Toxoplasma DNA, however, may provide a handle to study phylogenetic relationships among Coccidia and perhaps other Sporozoa at the molecular level.

\section{The cruciform is probably not present in vivo}

When the Toxoplasma circles are isolated in closed form, the palindrome shows up as a cruciform with an average arm length of $0.49 \mu \mathrm{m}$. This corresponds to an unwinding of $100 \cdot 0.98 / 11.7=$ $8.4 \%$ of the circle. This is equivalent to a superhelix density in the molecule without cruciform of -0.084 , assuming that the tailed circles do not contain remaining supertwists. This superhelix density is in the range observed for other covalently continuous DNAs.

Our results strongly suggest that the palindrome is not present as cruciform in vivo. Our main arguments for this conclusion are based on the thermodynamics of cruciform formation [13,14]. The initial formation of a branch requires energy to break a minimum of $3 \mathrm{bp}$, which remain unpaired in the top of the cruciform stem, and to overcome the loss of stacking interactions due to the generation of two junctions between cruciform arms and main DNA helix. This energy can be provided by superhelicity. The $\Delta G$ of superhelix formation increases with the square of $\sigma$ in the range of interest (Ref. 14 and M. Gellert, personal communication) and Courey and Wang [34] have directly shown that cruciforms start to form at $-\sigma=0.03$. Once an initial cruciform has been formed, branch migration can probably occur without significant energy changes, because such migration does not entail any net change in base pairing or base stacking, provided that the palindrome contains a perfect inverted repeat. The result will be that all superhelical turns will be dissipated into the cruciform, and any further negative supertwists brought in by a gyrase will merely serve to lengthen the stems of the cruci- form until all of the palindrome has been taken up in the cruciform. Only then will supercoils build up again in the circle.

It follows from this argument that the steadystate superhelix density of these Toxoplasma circles in vivo must be below the critical value where cruciform formation starts. If this were not the case, we would have found circles with $1.7-\mu \mathrm{m}$ tails rather than $0.5 \mu \mathrm{m}$ and with visible twists instead of none. We conclude, therefore, that a substantial fraction of the negative superhelicity found in the isolated circles, as judged from the presence of cruciforms, is the result of removal of proteins or other factors that make the DNA underwound in vivo relative to our in vitro conditions. Although we consider this the most plausible interpretation of our data, it is not the only one. It is also possible that there are proteins bound to the palindrome in vivo that actively counteract cruciform formation. Another possibility comes from recent experiments of Courey and Wang [34] and M. Gellert (personal communication) which show that the kinetic barrier for cruciform formation is in two cases much larger than previously thought. At a superhelix density of -0.05 their DNA was completely converted into cruciform by brief heating. This cruciform was stable at $37^{\circ} \mathrm{C}$, but in the same buffer the cruciform did not form at $37^{\circ} \mathrm{C}$. Likewise, the formation of cruciforms may be kinetically impeded in Toxoplasma, but it is doubtful whether this could fully account for our results. The negative superhelix density calculated for the Toxoplasma circles $(0.08)$ is much higher than that employed in the plasmid experiments mentioned (0.05). Moreover, the eukaryote Toxoplasma multiplies much more slowly than $E$. coli. Even the proliferative stages used in our experiments have a doubling time of 6-8 $\mathrm{h}$ and some stages of this organism (the cystozoites) can remain dormant in homeothermal vertebrates for periods longer than that needed for a thesis project.

All these alternative explanations for our finding lead to the same final conclusion that no cruciform exists in vivo in Toxoplasma. This is in line with the suggestion that cruciforms resemble the Holliday structures formed as intermediates in recombination. Such structures should be unstable in the cell because they are attacked by specific endonucleases [35]. 


\section{The putative dimer circles}

There is little doubt that the $23-\mu \mathrm{m}$ tailed circles are really dimers of the tailed $12-\mu \mathrm{m}$ circles. They are double the contour length of the tailed circle monomers and in the dimers with two sets of tails the two sets are separated by exactly half the contour length. This indicates that the monomers are linked head-to-tail in the dimer. If the only energy investment in cruciform formation lies in the breakage of the basepairs that remain unpaired in the top of the cruciform arms, one would expect the preferred configuration of dimers to be the one in which only two tails of double length are present. We find, however, that two of the seven dimers are of the four-tail type. Why is this? The moment the Toxoplasma cells are lysed and proteins are removed from the circular DNA, the superhelix density of the molecule will rise above the critical value required for cruciform formation. In a dimer two cruciforms can form. If one forms before the other, it will rapidly lower the superhelix density below the critical value and prevent the other cruciform from forming at all. This may be the origin of some or all of the two-tailed dimers. In some molecules both cruciforms will be formed simultaneously when the cells are lysed. Since the energy investment is in the initial formation of the cruciform and not in its lengthening, the dimer with four tails is thermodynamically unstable, because the dimer with two tails of double length has fewer broken basepairs. It should, therefore, be possible by branch migration to convert one cruciform into the other without energy input. Hence, the existence of dimers with four tails requires an explanation. Two possibilities can be considered.

(a) The palindrome is imperfect and the imperfection is greater towards the ends of the palindrome than in the middle. Although we find this rather unlikely, in view of the variability in tail size of monomer circles (cf. Table I), this possibility cannot be ruled out.

(b) Although the two-tailed dimer is more stable than the four-tailed one, it is not easy to cash in the free energy involved, because this is only generated in the last step when one cruciform disappears. The process of converting two cruciforms into one should, therefore, resemble an unbiased random walk, and with tails of $1500 \mathrm{bp}$ this walk may last too long to allow all four-tailed circles to metamorphose into two-tailed circles under the conditions of our experiments.

The low rate at which long cruciforms may be absorbed by the circle may also account for two other observations. First, we have found a single dimer circle with only two 'short' tails. This could by a nicked dimer which has lost part of its tails. Second, we have had difficulties in demonstrating that digestion of tailed circles with $S_{1}$ nuclease, which should cut at the top of the cruciform (cf. Refs. 17 and 18), leads to loss of tailed circles. Such a loss was only observed in experiments in which circles without tails were also linearized (experiments not shown).

Circular dimers have been found only rarely in mitochondrial DNAs [36] and it is not clear why they should be present so abundantly in our covalently continuous DNA fraction. It is possible that this is a peculiarity of protozoa, because we have also found a high frequency of molecules with the size of free maxi-circle oligomers in a covalently continuous DNA fraction from Trypanosoma brucei (unpublished results).

\section{Ethidium bromide blocks branch migration}

An unexpected result was obtained when the tailed circles were spread in the presence of relatively high concentrations of ethidium bromide. Highly twisted circles were observed, as anticipated, but these still contained tails of the same size as the $0.5-\mu \mathrm{m}$ tails found in the absence of ethidium bromide. Intercalation of ethidium bromide in the DNA helix leads to unwinding. As a consequence, right-handed superhelical turns disappear and so should the cruciform. The fact that this does not occur must mean that intercalation of ethidium bromide inhibits the branch migration required for cruciform elimination. At high ethidium bromide concentration branch migration appears to be completely blocked (the cruciform is crucifixed), because the tails of the cruciforms in twisted circles are not significantly shorter than in tailed circles spread in the absence of ethidium bromide. This interpretation is supported by our observation that the tails can be eliminated when ethidium bromide is allowed to diffuse into the solution, leading to a slow rise in its concentration. An analogous trapping of the 
DNA in the cruciform state has also been observed with another palindrome-containing circle by $\mathrm{M}$. Gellert (personal communication).

After completing this work, we learnt from R.C. Warner that Fishel [37] has found that ethidium bromide inhibits branch migration in figure- 8 DNA molecules, $40 \mu \mathrm{g}$ ethidium bromide per $\mathrm{ml}$ reducing the rate almost to zero. This supports our interpretation of the effects of ethidium bromide on the Toxoplasma cruciforms.

\section{The function and stability of long inverted repeats}

Long inverted repeats have been found in chloroplast DNAs of most higher plants (see Ref. 38) and in the mitochondrial DNAs from the protozoan Tetrahymena [39], the yeast Kloeckera africana [40] and the unicellular water mould Achlya ambisexualis [41]. In all cases the repeats code for ribosomal RNAs and they are usually separated by at least $1 \mathrm{~kb}$ of non-repeated DNA; the only adjacent repeats are present in the DNAs from Kloeckera and Toxoplasma. It seems likely that the active DNA recombination systems present in these organelles [42] would tend to eliminate the extra copy of the ribosomal RNA genes if the duplicated gene was present as a tandem repeat. The inverted repeat may, therefore, be the only form in which a duplicated gene can be stably retained in these organelle genomes.

Plasmids containing large palindromes are unstable in E. coli (cf. Refs. 6 and 22) and this is usually attributed to deletions arising during replication, because the polymerase skips part of the palindrome. It is possible that such disasters are avoided in mitochondria, because the polymerase has basically different properties. Another possibility is that the replication of the palindrome-containing circles starts at the junction in the palindrome. In this case the hairpin will never form in the lagging template strand during replication.

The experimental results of $\mathbf{M}$. Gellert quoted in this paper have recently been published in Ref. 43.

\section{Acknowledgements}

We are indebted to Dr. J.C. Wang (Department of Biochemistry and Molecular Biology, Harvard
University, Cambridge, MA 02138, U.S.A.), Dr. M. Gellert (Laboratory of Molecular Biology, National Institute of Arthritis, Diabetes, and Digestive and Kidney Diseases, National Institutes of Health, Bethesda, MD 20205, U.S.A.), Dr. B. Kemper (Institut für Genetik, Köln, F.R.G.) and Dr. R.C. Warner (Department of Molecular Biology and Biochemistry, University of California, Irvine, CA, U.S.A.) for communicating unpublished or inaccessible results, and to Dr. Wang, Dr. Gellert and Professor H.S. Jansz (Laboratory of Physiological Chemistry, State University Utrecht, Utrecht, The Netherlands) for stimulating discussions and helpful advice. We thank Miss. Janny Van den Burg for excellent technical assistance and Mr. J. Woons for help with photography. This work was supported in part by a grant to P. Borst from the Foundation for Fundamental Biological Research (BION), which is subsidized by The Netherlands Organization for the Advancement of Pure Research (ZWO). We wish to thank the Staff of the Laboratory of Electron Microscopy and Molecular Cytology for their hospitality and for their generous technical assistance with the electron microscope.

\section{References}

1 Bauer, W. and Vinograd, J. (1971) in Progress in Molecular and Subcellular Biology (Hahn, F.E., ed.), Vol. 2, pp. 181-215, Springer Verlag, Heidelberg

2 Bauer, W.R. (1978) Annu. Rev. Biophys. Bioeng. 7, 287-313

3 Cozzarelli, N.R. (1980) Science 207, 953-960

4 Ruttenberg, G.J.C.M., Smit, E.M., Borst, P. and Van Bruggen, E.F.J. (1968) Biochim. Biophys. Acta 157, 429-432

5 Vinograd, J., Lebowitz, J., Radloff, R., Watson, R. and Laipis, P. (1965) Proc. Natl. Acad. Sci. U.S.A. 53, 1104-1111

6 Gellert, M., Mizuuchi, K., O’Dea, M.H., Ohmori, H. and Tomizawa, J. (1979) Cold Spring Harbor Symp. Quant. Biol. 43, 35-40

7 Mizuuchi, K., Mizuuchi, M. and Gellert, M. (1982) J. Mol. Biol. 156, 229-243

8 Smith, G.R. (1981) Cell 24, 599-600

9 Sinden, R.R. and Pettijohn, D.E. (1981) Proc. Natl. Acad. Sci. U.S.A. 78, 224-228

10 Sinden, R.R. and Pettijohn, D.E. (1982) J. Mol. Biol. 162, 659-677

11 Gierer, A. (1966) Nature 212, 1480-1481

12 Müller, U.R. and Fitch, W.M. (1982) Nature 298, 582-585

13 Hsieh, T.-S. and Wang, J.C. (1975) Biochemistry 14, 527-535

14 Vologodskii, A.V. and Frank-Kamenetskii, M.D. (1982) FEBS Lett. 143, 257-260 
15 Benham, C.J. (1982) Biopolymers 21, 679-696

16 Woodworth-Gutai, M. and Lebowitz, J. (1976) J. Virol. 18, 195-204

17 Panayotatos, N. and Wells, R.D. (1981) Nature 289, 466-470

18 Lilley, D.M.J. (1981) Nucleic Acids Res. 9, 1271-1289

19 Shishido, K. (1980) FEBS Lett. 111, 333-336

20 Panyutin, I.G., Lyamichev, V.I. and Lyubchenko, Yu.L. (1982) FEBS Lett. 148, 297-301

21 Singleton, C.K. and Wells, R.D. (1982) J. Biol. Chem. 257, 6292-6295

22 Bergsma, D.J., Olive, D.M., Hartzell, S.W., Byrne, B.J. and Subramanian, K.N. (1982) Gene 20, 157-167

23 Overdulve, J.P. (1978) Proc. Koninkl. Nederl. Akad. Wetensch. (Amsterdam), Ser. C 81, 1-18

24 Cornelissen, A.W.C.A., Overdulve, J.P. and Van der Ploeg, M. (1984) Parasitology, in the press

25 Borst, P. and Fase-Fowler, F. (1979) Biochim. Biophys. Acta $565,1-12$

26 Davis, R.W., Simon, M. and Davidson, N. (1971) Methods Enzymol. 21, 413-428

27 Davis, R.W. and Davidson, N. (1968) Proc. Natl. Acad. Sci. U.S.A. $60,243-250$

28 Sinclair, J.H., Stevens, B.J., Gross, N. and Rabinowitz, M. (1967) Biochim. Biophys. Acta 145, 528-531

29 Stüber, D. and Bujard, H. (1977) Mol. Gen. Genet. 154, 299-303
30 Lilley, D.M.J. (1980) Proc. Natl. Acad. Sci. U.S.A. 77, 6468-6472

31 Kleinschmidt, A.K., Rüter, H., Hellmann, W., Zahn, R.K., Dokter, A., Zimmermann, E., Rübner, H. and Al Ajwady, A.M. (1959) Z. Naturforsch. 14b, 770-779

32 Borst, P. and Flavell, R.A. (1976) in Handbook of Biochemistry and Molecular Biology (Fasman, G.D., ed.), 3rd Edn., Vol. 2, pp. 363-374, CRC Press, Cleveland

33 Grimes, G.W., Mahler, H.R. and Perlman, P.S. (1974) J. Cell Biol. 61, 565-574

34 Courey, A.J. and Wang, J.C. (1983) Cell 33, 817-829

35 Mizuuchi, K., Kemper, B., Hays, J. and Weisberg, R.A. (1982) Cell 29, 357-365

36 Clayton, D.A. and Smith, C.A. (1975) Int. Rev. Exp. Pathol. 14, 1-67

37 Fishel, R.A. (1980) Ph.D. Thesis, University of California, Irvine.

38 Palmer, J.D. (1983) Nature 301, 92-93

39 Goldbach, R.W., Bollen-de Boer, J.E., Van Bruggen, E.F.J. and Borst, P. (1978) Biochim. Biophys. Acta 521, 187-197

40 Clark-Walker, G.D., McArthur, C.R. and Sriprakash, K.S. (1981) J. Mol. Biol. 147, 399-415

41 Hudspeth, M.E.S., Shumard, D.S., Bradford, C.J.R. and Grossman, L.I. (1983) Proc. Natl. Acad. Sci. U.S.A., in the press.

42 Gillham, N.W. (ed.) (1978) Organelle Heredity, Raven Press, New York

43 Gellert, M., O’Dea, M.H. and Mizuuchi, K. (1983) Proc. Natl. Acad. Sci. U.S.A. 80, 5545-5549 